\title{
UM TESTEMUNHO DO CÁRCERE: O CASO SOBREVIVENTE ANDRÉ DU RAP (DO MASSACRE DO CARANDIRU)
}

\author{
Aulus Martins $^{1}$ \\ Isadora Mattos ${ }^{2}$
}

Resumo: $O$ presente artigo tem por objetivo analisar a chamada "Nova literatura de cárcere" brasileira através da obra Sobrevivente André Du Rap (do massacre do Carandiru) (2002), do jornalista Bruno Zeni a partir do relato de André Du Rap. Tal tendência da literatura nacional apresenta-se como uma quebra do paradigma de representação da experiência prisional ao trazer para o centro da discussão o relato de um preso comum, em contraposição aos relatos de presos políticos, até então dominantes na categoria. A análise procurou verificar a pertinência da aparente familiaridade da obra com 0 testimonio, corrente dominante de literatura de testemunho na América Latina durante a segunda metade do século XX.

Palavras-chave: literatura de cárcere; testimonio; André Du Rap.

Abstract: This article aims to analyze the "new prison literature" through the work of Sobrevivente André Du Rap (do massacre do Carandiru) (2002), by the journalist Bruno Zeni from reporting André Du Rap. This trend of national literature is presented as a break from the paradigm of representation of the prison experience to bring to the center of the discussion the story of an ordinary prisoner, in contrast to reports of hitherto dominant political prisoners in the category. The analysis sought to verify the relevance of the apparent familiarity of the work with the testimonio, current dominance of witness literature in Latin America during the second half of the twentieth century.

Keywords: prison literature; testimonio; André Du Rap

\footnotetext{
${ }^{1}$ Doutor em Letras. Professor do Programa de Pós-Graduação em Letras da UFPel. E-mail: aulus.mm@gmail.com

${ }^{2}$ Graduada em Letras Português/Espanhol pela UFPel. Bolsita PIBIC/CNPq (2012). E-mail: isadoranunez@gmail.com
} 


\title{
1. Uma nova literatura de cárcere no Brasil
}

Autores como Carla Sena Leite (2006), Maria Rita Palmeira (2006 e 2011) e, principalmente, Márcio Seligmann-Silva (2003 e 2006) veem elaborando a hipótese do surgimento de uma nova tendência na literatura brasileira: a crescente produção de literatura carcerária que representa a experiência do preso comum. Essa tendência apresenta-se como uma quebra no paradigma de literatura de cárcere no país, na qual, até então, predominavam narrativas que veiculavam a experiência do preso político, como, por exemplo, as Memórias do Cárcere (1953) de Graciliano Ramos.

Sobre essa nova literatura de cárcere brasileira, Seligmann-Silva aponta a violência presente na sociedade como um dos motivos para a origem desse "boom", que se deu principalmente a partir dos relatos sobre a experiência nas prisões do estado de São Paulo:

\begin{abstract}
Não creio que se possa indicar uma origem única e simples para esse fato, mas é certo que entre os motivos para a prosperidade dessa modalidade de literatura encontra-se, antes de mais nada, o enorme interesse atual do público leitor brasileiro por tudo o que tem a ver com violência e a sua própria sobrevivência em uma sociedade que se torna cada vez mais polarizada entre os ricos em seus "bunquers" e os pobres sendo perseguidos e enviados para as cadeiras super lotadas. (Seligmann-Silva: 2003, 31)
\end{abstract}

Essa mesma violência, segundo o autor, deixa marcas claras nas características estruturais dos textos integrantes do "boom". Ela influenciaria a escolha do léxico, a organização sintática dos relatos, bem como no caráter "oralizado" presente na maioria dos relatos.

Já autores como Carla Sena Leite (2006) e Maria Rita Palmeira (2006) e (2011) destacam como característica comum a essas obras o relato do chamado Massacre do Carandiru, ocorrido em 2 de outubro de 1992 e que deixou um simbólico saldo de 111 presos mortos. São apontadas ainda como características desses relatos a representação de valores como coletividade e humildade, supostamente adquiridos dentro do regime carcerário, bem como a defesa e subordinação aos códigos de convivência entre os presos, mesmo depois da saída do sistema carcerário.

Como exemplos dessa nova literatura de cárcere brasileira podem ser 
apontadas obras como Memórias de um sobrevivente (2001) de Luiz Alberto Mendes, que além de ser uma das primeiras a retratar a experiência do preso comum, possui, como afirma Seligmann-Silva (2006), uma característica sui generis em comparação às outras obras do "boom": o relato de Luiz Alberto Mendes não trata, como ponto central da narrativa, a representação do massacre de outubro de 1992, mas sim a passagem de um preso comum desde sua infância até a idade adulta — durante os anos de ditadura militar. Quanto às outras obras pertencentes a esse conjunto e que trazem a experiência prisional marcada pelo massacre, podem ser destacadas: Sobrevivente André Du Rap (do massacre do Carandiru) (2002) de autoria do ex-dentento José André de Araújo e o jornalista Bruno Zeni, obra privilegiada pelo artigo; Diário de um detento: o livro (2001) de Jocenir; Pavilhão 9: paixão e morte no Carandiru (2001) de Hosmany Ramos e Marques Viana.

\section{A nova literatura de cárcere e a literatura de testemunho}

Devido ao fato de que esses textos da "nova literatura de cárcere brasileira" pretendem-se veiculadores de uma experiência real, é inevitável relacioná-los com a literatura de testemunho. Como a expressão já sugere, essa é uma literatura com base no real na qual alguém que presenciou, testemunhou algo, transmite, através de um depoimento, a experiência vivida. Há basicamente dois tipos de testemunhas. Um deles é o testis, um terceiro que não está necessariamente implicado de forma direta no fato, mas o presencia e conta o que viu. O outro é o superstes, que, além de estar diretamente implicado no fato, sobreviveu e conta sua experiência de sobrevivência frente ao fato que na maioria das vezes apresenta-se como um episódio traumático na vida da testemunha (Agamben: 2008, 25-38). Neste último tipo de testemunha, está contida a ideia de mártir, ou seja, aquele que passou por um martírio e sobreviveu para fazer com que a experiência pela qual passou seja conhecida pelos outros.

A literatura de testemunho gera muita discussão em torno de si e uma das principais questões reside em se, de fato, pode ser considerada como um 
gênero literário, já que pretende veicular uma experiência calcada no real. Muitos são os teóricos que discorrem sobre a questão, chamando atenção para o fato de que a literatura de testemunho põe em discussão a noção préestabelecida de texto literário como ficção. Alguns autores como Valeria de Marco (2004) e Márcio Seligmann-Silva (2003 e 2006) ressaltam que o testemunho é uma representação, uma rearticulação do fato presenciado através da memória, logo traria já em sua constituição o conflito entre literalidade e literariedade como constituinte essencial. Conflito este que marcaria o caráter literário do gênero, que, segundo Marco (2004), está presente em todos os gêneros literários conhecidos até então: não obedece a uma formulação e regras fixas. Também se apresenta como argumento a favor da percepção da literatura de testemunho como gênero, a instituição em 1970 da categoria "Testimonio" no júri do prêmio Casa de Las Américas, frente ao grande número de produções inscritas para o prêmio naquela época e que fugiam ao conceito de romance.

No contexto mundial, podemos identificar duas correntes principais de literatura de testemunho, cada uma com suas particularidades. A da shoah e o testimonio latino-americano. A literatura da shoah diz respeito ao relato de sobreviventes dos campos de concentração nazistas e suas principais características são: o dever de narrar os horrores vistos nos campos de concentração para que não voltem a se repetir e em memória daqueles que não sobreviveram; o constante embate entre memória, trauma e narração; a impossibilidade de simbolizar plenamente através da linguagem as atrocidades testemunhadas. A obra mais representativa dessa literatura é o livro $E$ isto um homem? de Primo Levi, sobrevivente de Auschwitz. Já no contexto do testimonio latino-americano, encontramos uma grande discussão devido à diversidade de textos e conteúdos que a nomenclatura abarca, bem como a complexidade que eles podem adquirir. Ana Maria Sanchez (s/d) e Valeria de Marco (2004), dentre outros, apresentam como testimonio tanto relatos dos presos políticos das ditaduras ocorridas na segunda metade do século XX na América Latina, a vida de mártires das revoluções como, por exemplo, dos líderes sandinistas na Nicarágua e, por último, a acepção considerada hegemônica no contexto da América Hispânica: os relatos de testemunhas representativas de grupos subalternos social, cultural e economicamente, bem 
como explorados e/ou dizimados pela violência estatal. Alguns críticos e teóricos como Marco (2004) dizem que esta acepção hegemônica é fruto de um projeto político de cuba, já que os primeiros textos surgiram lá e com o intuito de dar voz ao proletariado esquecido, para que se conhecesse a história daqueles que nunca tiveram voz ativa na sociedade e para que sua cultura não se perdesse:

Seria um projeto da Revolução Cubana, um estímulo à construção da verdadeira história de opressão da dominação burguesa na América Latina, feita a partir da experiência e da voz dos oprimidos. A literatura de testemunho praticada, teorizada e divulgada por Barnet seria fomentada pelo poder institucional e teria, a partir de então, conquistado o estado de cânon. (Marco: 2004, 46-47)

São obras paradigmáticas dessa acepção Me llamo Rigoberta Menchú y saí me nació la conciencia (1983) de Rigoberta Menchú e Elizabeth Burgos, em que é narrada a opressão aos povos indígenas da Guatemala durante a ditadura militar na segunda metade do século XX e Biografía de un cimarrón (1966) de Esteban Montejo e Miguel Barnet, em que é narrada a experiência de vida de Miguel Montejo, um ex escravo cubano negro que tinha 105 anos na época em que foi entrevistado por Barnet. Sobre a constituição dos testimonios, pode-se dizer que são basicamente feitos de transcrições de entrevistas concedidas pelas testemunhas e materiais gráficos como fotografias, documentos e mapas.

A principal característica desta acepção hegemônica do testimonio latino-americano é a presença de um narrador de ofício, um editor ou ainda um gestor que pode ser um antropólogo, um etnólogo, um jornalista ou um escritor que fará vir à tona a identidade desse grupo social subalterno à força estatal, como o são Elizabeth Burgos e Miguel Barnet nos exemplos supracitados. Sua presença é justificada pelo fato de que, na maioria dos casos, a testemunha que conta sua experiência (comum a todos do grupo e, por isso mesmo representativa) é ágrafa. Sua presença também se explica pela necessidade de uma figura pertencente aos circuitos culturais "elevados" para que o livro seja 
legitimado pela cultura letrada. Esse gestor possuiria o dever ideológico de fazer com que a fala, o discurso, dessa testemunha seja transmitido da maneira mais fiel possível para que a identidade dela e de seu grupo social realmente transpareça através do relato. Para que isso ocorresse, seria dever do gestor apagar-se do relato ou então fundir sua identidade com a da testemunha, o que daria voz total a ela no relato.

Essa modalidade de testimonio mediado por um intelectual, ao mesmo tempo em que levanta o pressuposto político de igualdade e justiça social de fazer emergir a identidade de um grupo subalterno, apresenta problemas em sua formulação e práticas discursivas. Isso porque a testemunha, muitas vezes analfabeta, entrega seu relato ao gestor, que pode acabar descaracterizando e manipulando aquilo que the é dito. Sobre os riscos da atuação do gestor, Sklodowska (1993) alerta ao fato de que ao editar e transformar o discurso da testemunha em um discurso aceitável pelos padrões culturais das classes detentoras do conhecimento (como, por exemplo, modificar a fala da testemunha em nome de uma proteção contra preconceitos linguísticos), o gestor pode estar perdendo a essência daquilo que the é narrado e caindo na prática que Geertz (apud Sklodowsk, 1993) chama de "ventriloquia etnográfica" (p.83) e que, segundo a autora, Elizabeth Burgos faz com a fala de Rigoberta Menchú em Me llamo Riboreta Menchú y así me nació la concinencia (1983), a obra paradigmática do testimonio mediado:

Para Burgos "efectuar el paso de la forma oral a la escrita" (17) envuelve una serie de procedimientos nítidos cuya legitimidad le parece incuestionable. Como si no hubiera problemas formales, éticos o ideológicos en el hecho de descifrar cintas, leer las transcripciones, establecer un fichero por temas para organizar los capítulos, suprimir las preguntas, u ordenar el manuscrito cronológicamente para hacerlo más asequible. (Sklodowsk: 1993, 84)

A autora também aponta para o caráter dúbio que a utilização de materiais gráficos como fotografias, documentos, testemunhos de outras pessoas, prólogos e epílogos, bem como a montagem do livro podem ter: ao mesmo tempo em que confirmam o relato da testemunha e conferem fidelidade a ele, podem acabar relativizando o relato justamente pelo excesso de fontes para confirmar o que diz a testemunha (p.87).

|22| Revista Eletrônica Literatura e Autoritarismo, no 24 - julho a dezembro de 2014 - ISSN 1679-849X http://cascavel.ufsm.br/revistas/ojs-2.2.2/index.php/LA/index 


\section{Sobrevivente André Du Rap (do massacre do Carandiru) e o testimonio} latino-americano

A obra Sobrevivente André Du Rap (do massacre do Carandiru) (2002) é representativa da "nova literatura de cárcere brasileira" e considerada o primeiro relato em livro sobre o mencionado evento do Carandiru. Ela é aproximada por muitos críticos e teóricos à acepção hegemônica de testimonio latino-americano. Isso porque possui uma autoria híbrida, sendo composta pela transcrição das entrevistas concedidas pelo ex- detento José André de Araújo ao jornalista Bruno Zeni, indicado na capa do livro como coordenador editorial, o que lembra, por certo, a figura do gestor presente nas obras paradigmáticas da corrente:

\footnotetext{
Esta junção de narrativa (gravada) e a transcrição executada por um jornalista faz desta obra talvez a mais autêntica manifestação do testimonio dentro da literatura carcerária brasileira; mas de um testimonio particularmente sofisticado, que não cai no lugar comum do "gênero carcerário", nem no das histórias detetivescas, ou ainda na sucessão de anedotas (...) (Seligmann-Silva: 2003, 44)
}

Além disso, a obra é composta por materiais gráficos tais como fotografias e cartas, o que também reforça a familiaridade desse projeto com o testimonio. Entretanto, trata-se de uma aparente familiaridade. Seligmann-Silva (2003) já aponta para esse conteúdo ao afirmar que a obra é uma manifestação "particularmente sofisticada" da acepção. Para verificar dessa familiaridade, se faz necessária uma análise dos pressupostos presentes na obra, bem como as estratégias discursivas utilizadas pelos autores e, principalmente por Bruno Zeni na composição de Sobrevivente André Du Rap (do massacre do Carandiru).

\section{A atuação de Bruno Zeni como gestor}

Em um primeiro momento, Bruno Zeni aparentemente atua como um gestor clássico do testimonio. Essa postura pode ser verificada no prólogo do 
livro, em que o jornalista destaca o fato de ter mantido o caráter oral da fala de André na busca de ser o mais fiel possível às "particularidades" do ex-detento, o que demonstra seu cuidado com a manutenção da forma do discurso da testemunha:

$\mathrm{Na}$ edição do texto, procurei ser o mais fiel possível às particularidades da fala de André - mantive inclusive as suas incongruências e incorreções - por acreditar que não se pode separar a forma e o conteúdo daquilo que se diz, se escreve ou se cria. (Du Rap: 2002, 9)

Entretanto, logo a seguir, Zeni afirma ter deslocado para o início da seção "Depoimento" a parte do relato em que André narra o episódio do massacre. $O$ jornalista também afirma ter suprimido as perguntas norteadoras das entrevistas e outras intervenções suas durante o relato, bem como declara ter escolhido trechos dos depoimentos que André gravou sozinho para a composição da seção "Free Style (de improviso)".

Ao declarar abertamente sua intervenção e manipulação dos dados obtidos para a composição do livro, Zeni nega a conduta clássica do gestor do testimonio. Esse procedimento é, naturalmente, confrontado com a declarada manutenção do caráter oral do relato de André. Desse modo, em Sobrevivente André Du Rap (do massacre do Carandiru), a posição do gestor não tende a anular-se diante do discurso da testemunha. Essa diferença é acentuada pela incorporação do artigo acadêmico "Uma voz sobrevivente" assinado pelo próprio Zeni ao final do livro, que, assinalando a oposição entre o discurso do jornalista e o discurso do ex-detento acaba, de certo modo, por resolver uma das principais problemáticas do testimonio.

Trata-se da impossibilidade de seguir à risca o compromisso ideológico de apagamento da identidade e de não influência do gestor durante o relato ou, ainda, a impossibilidade de fusão das identidades da testemunha e do gestor. Tal questão é apontada por Elzbieta Sklodowska (1993), que destaca o fato de que gestores como Burgos ou Barnet utilizarem palavras como "'fidelidad', 'simbiosis', 'identificación' o 'aproximación'” (p.85) significaria uma tentativa de "erigir defensas contra una posible acusación de manipulación y paternalismo" (p.85), o que por si só já indica que talvez a fusão de identidades apresente-se 
como algo ameaçador e que a manipulação do material seria inevitável, ainda que o compromisso ideológico de não distorcer o discurso do eu subalterno guie o processo de produção e montagem do testimonio. A autora vai ainda mais a fundo e critica o fato de que, ao produzirem o testimonio na ânsia de fazer com que somente o discurso da testemunha transpareça, os gestores não refletem criticamente sobre suas produções, o que poderia contribuir para 0 desenvolvimento de um testemunho mais elaborado em termos formais e, consequentemente, maiores chances de atingir seus objetivos ideológicos de levar a identidade de um grupo subalterno aos circuitos culturais mais prestigiados:

El resultado de estas preocupaciones son (...) textos depurados de preguntas y de verba dicendi. Textos monologizados - en el sentido ideológico más que gramatical - que pretenden sustentar la ilusión de fusión de identidades y negar lo obvio: el hecho de ser productos de resistencias y acomodaciones. (Sklodowsk: 1993, 85)

A decisão pela manutenção do caráter oral da fala de André não serve somente para marcar a diferença de discurso e a impossibilidade de fusão das identidades de gestor e testemunha. Trata-se, ainda, de uma estratégia para destacar a experiência do trauma de André:

A opção pela manutenção das arestas da narrativa oral busca conservar as marcas do seu trauma, identificadas na forma do seu relato, e que corriam o risco de se diluir se procurássemos consertar ou reescrever o seu depoimento. (Du Rap: 2002, 214)

Marcas estas que se apresentam da seguinte maneira no transcorrer do relato:

O tempo da ação é circular, não obedece linearmente ao desenrolar dos acontecimentos. $O$ trabalho da memória vai e vem: quando o depoimento chega a um ápice de tensão tal que parece não ter mais nada a acrescentar sobre a chacina, tudo recomeça. (Du Rap: 2002, 207) 
Essa dimensão formal do trauma de André também está expressa no modo fragmentado como o jornalista organizou o livro: Na seção "Depoimento", André conta o episódio do massacre, como foi preso, a chegada ao Carandiru, seu casamento dentro da cadeia e a vida em si durante sua passagem pelo sistema prisional; Logo após esta seção, há uma seleção de 18 fotografias que mostram André entre companheiros de prisão, com integrantes da pastoral carcerária e desenvolvendo trabalhos sociais após sua saída da detenção; A seguir, está alocada a seção "Fragmentos de uma correspondência", na qual aparecem cartas que André recebeu durante o período em que esteve preso; Em seguida está a seção "Free Style (de improviso)", composta por uma seleção feita por Zeni do relato que André gravou sozinho e que traz basicamente os mesmos temas já tratados na seção "Depoimento"; Logo após, a seção "Aliados" traz uma série de depoimentos de amigos de André, nos quais seus "aliados" contam como conheceram o ex-detento e falam do seu engajamento em movimentos e projetos sociais; Por último, está o já citado artigo "Uma voz sobrevivente", no qual Bruno Zeni conta como conheceu André, de onde surgiu a ideia de contar o massacre a partir do "(...) ponto de vista de quem sofreu o trauma na carne e no espírito (...)” (Du Rap: 2002, 199) e faz uma análise da narrativa do ex-detento, trazendo como principais suportes teóricos Ecléa Bosi, Walter Benjamin, em textos que tratam da relação da escritura com a memória e o trauma. Em seu texto sobre Memórias de um sobrevivente, Seligmann-Silva diz que em oposição ao modelo próximo do "realismo convencional" adotado por Mendes, Zeni opta por "aderir a uma estética da fragmentação que, na sua forma descontínua mimetiza a catástrofe representada" (Seligmann-Silva: 2006, 35).

Já Maria Rira Palmeira (2006) destaca a seção "Free Style (de improviso)" como uma replicação da base do próprio livro. Fato é que a estrutura formal em que o livro foi montado mimetiza e reduplica a dimensão formal do trauma de André, que se expressa pela oralidade de seu discurso, em que os episódios vão e vem, com elipses e acréscimos, devido aos movimentos de rememoração. Um exemplo disto é a narração de uma cena específica do massacre, que é contada logo no início de seu "Depoimento" e é retomada mais de cem páginas depois: 
No segundo andar, numa distração deles, a gente se jogou no meio dos corpos que estavam ali no corredor. Foi a única alternativa. (...) Nesse momento chegou um PM, um tenente ou um capitão, não sei bem, falando:

- Fala pra quem tiver vivo levantar e descer pro pátio.

Aí todo mundo desceu correndo com tudo. (...) Todo mundo pelado com a mão na cabeça, alguns feridos. (...) outros se recusavam a ir e levavam pontapés, a polícia jogava os cachorros em cima. (...) Vi cara ser mutilado pelos cachorros na minha frente. (Du Rap: 2002, 23-34)

Me joguei no meio dos corpos, e fiquei ali, me fingindo de morto. Aí os caras vinham, pisavam em cima, chutavam. Sentia aquela dor, mas não podia gemer, você não podia fazer nada. (...) Aí teve um momento que cessou um pouco, no quinto andar. Eles fecharam todos no xadrez, depois abriram, falaram: - Quem estiver vivo sai correndo com a mão na cabeça, nu.

Naquele momento nós saímos, eu mais outro companheiro, saímos disparando, sem olhar pra trás. (Du Rap: 2002, 176177)

Assim, fica claro que o objetivo de Zeni não é trazer à tona a identidade de um grupo subalterno submetido à força estatal. Seu foco está na evocação, através na narração individual do trauma de André, de uma "memória coletiva" ou uma "memória compartilhada" por aqueles que sofreram o trauma. Coletividade mnemônica expressa no uso recorrente do "a gente", que evoca o conjunto dos companheiros ou "aliados" de luta de André dentro do sistema prisional, conjunto no qual estão contemplados os companheiros que foram mortos no massacre:

Um preocupado com a segurança do outro, dos companheiros da quebrada, seu irmão, seu cunhado, primo, parceiro - se acontecer alguma coisa a gente tá todo mundo junto. (Du Rap: 2002, 19)

A gente foi rendido nas celas. A polícia mandou a gente tirar a roupa e sair olhando pro chão, com a mão na cabeça. Fizeram a gente fazer fila. Formaram corredor polonês, um polícia de cada lado, e mandaram a gente correr. Deram chute, bica, cacetada, tiro. (Du Rap: 2002, 21-22)

E para que essa memória coletiva viesse à tona com todo o seu potencial, foi essencial que Bruno Zeni utilizasse as estratégias discursivas de 
manutenção do caráter oral de André, a marcação da diferença entre seu discurso e o da testemunha, bem como a forma escolhida na montagem do livro e a adição dos materiais gráficos como fotografias e cartas. Todos esses fatores juntos fizeram com que o testemunho atingisse seu objetivo e "ganhasse vida", em uma tradução livre das palavras de Randall (1992, p. 41).

\section{Uma nova forma de representação da violência}

Por todos os dados expostos, pode-se concluir que Bruno Zeni não age exatamente como um gestor clássico. Uma das explicações para isso é o fato de que a obra não possui os mesmos pressupostos ideológicos que os intelectuais da segunda metade do século XX defendiam. Não é objetivo do jornalista retratar a identidade subalterna de um grupo social excluído e reprimido pela força estatal. Mas sim representar e problematizar, por meio da experiência individual de André, o poder traumático que a violência exerce na vida de todos, o que vem a confirmar a afirmativa de Seligmann-Silva (2003), de que a relação entre política e arte na América Latina mudou desde a época em que eram produzidos os testimonios clássicos. Agora a violência retratada no relato não é mais somente promovida pelo Estado, mas está latente à sociedade e, por isso, exige uma nova forma de ser expressa. O que leva ao segundo motivo pelo qual Zeni não age como um gestor clássico: o jornalista não segue à risca os passos descritos em textos como o de Randall (1992). Ele problematiza essa forma (o que acaba por resolver antigos problemas e incongruências do gênero) na busca de fazer com que seu texto satisfaça as necessidades expressivas que o relato de André e o contexto brasileiro de violência exigem.

Isso poderia apontar para o desenvolvimento uma forma brasileira de produção de textos que se pretendem veiculadores de uma experiência real calcada na representação da violência. Uma forma com certa influência do testimonio, mas que não segue à risca pressupostos ideológicos problemáticos em nome de uma pretensa "solidariedade" narrativa. Uma forma na qual André e Zeni juntamente com autores como Drauzio Varella, Luis Alberto Mendes, Hosmany Ramos, Jocenir, entre outros, estariam dando os primeiros passos. 


\section{REFERÊNCIAS}

AGAMBEN. A testemunha. O que resta de Auschwitz. Trad. Salvino J. Assmann. São Paulo: Boitempo, 2008.

BEVERLEY, John. Anatomía del testimonio. Revista de Crítica Literaria Latinoamericana.[s.I.], Ano 13, № $25 . \quad 1987, \quad$ p. 7-16. http://www.jstor.org/stable/4530303 Acesso em: 30/11/2012.

DU RAP, André. Sobrevivente André Du Rap (do massacre do Carandiru). São Paulo:Labortexto Editorial, 2002.

GINZBURG, Jaime. Linguagem e trauma na escrita do testemunho. Conexão Letras, Porto Alegre, v. 3, p. 61-66, 2008.

LEITE, Carla Sena. Vozes do Carandiru: estudo comparativo de quatros narrativas do massacre. Encontro da Ulepicc - Brasil, I, 2006, Niterói.

MARTINS, Aulus Mandagará. O corpo e a voz da prisão: testemunho e experiência na literatura de cárcere. Acta Scientiarum. Language and Culture, v. 35, n. 3, p. 193-202, 2013. Disponível em http://eduem.uem.br/ojs/index.php/ActaSciLangCult/article/view/17732. Acesso em: 30/09/2012

MARCO, Valeria de. A literatura de testemunho e a violência de estado.[s.l.] Lua Nova. № 62. 2004, p. 45-68.

PALMEIRA, Maria Rita. Cada história uma sentença: anotações sobre Sobrevivente André Du Rap. Estudos de literatura brasileira contemporânea: Literatura e testemunho. Brasília. № 27.p.59-77. 2006.

"Neste mundo fora do mundo": estigma e literatura nas escritas prisionais recentes. Itinerários, Araraquara, n.32. p.75-82. 2011.

RANDALL, Margaret. ¿Qué es y cómo se hace un testimonio? Revista de Crítica Literaria Latinoamericana. Ano 18, № 36, La voz del Outro: Testimonio, Subalternidad y Verdad Narrativa. 1992, p.23-47. Disponível em www.jstor.org/stable/4530621. Acesso em: 30/11/2012

SANCHEZ, Ana Maria Amar. La ficción del testimonio. Buenos Aires: [s.n], [s.d.], p. 447-461.

SELIGMANN-SILVA, Márcio. Novos escritos dos cárceres: uma análise de caso. Luiz Alberto Mendes, Memórias de um sobrevivente. Estudos de literatura brasileira contemporânea: Literatura e testemunho. Brasília. n. 27.p. 35-58. 2006 
. Violência, Encarceramento, (In) Justiça: Memórias de histórias reais das prisões paulistas. Revista Letras, no 43. São Paulo: UNESP, 2003, p. 2947.

SKLODOWSKA, Elzbieta. ¿Ventriloquia o heteroglosia? (Barnet/Montejo; Burgos/Menchú). Revista de Crítica Literaria Latinoamericana. [s.I.], Ano 19, № 38. 1993, p.81-90. Disponíveç em http://www.jstor.org/stable/4530675. Acesso em: $30 / 11 / 2012$

YÚDICE, George. Testimonio y concientización. Revista de Crítica Literaria Latinoamericana. [s.I.], Ano 18, № 36, La voz del Outro: Testimonio, Subalternidad y Verdad Narrativa. 1992, p.211-232. Disponível em http://www.jstor.org/stable/4530631. Acesso em: 30/11/2012. 